
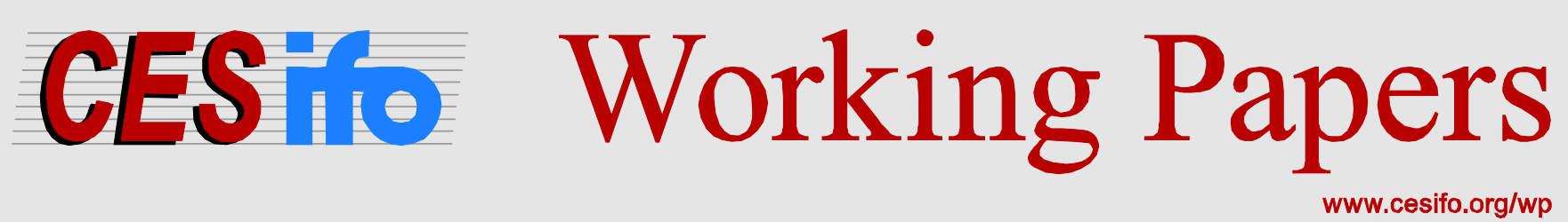

\title{
Taxation in Digital Media Markets
}

\author{
Hans Jarle Kind \\ Marko Koethenbuerger
}

\author{
CESIFO WORKING PAPER No. 6202 \\ CATEGORY 1: PuBliC FINANCE \\ NOVEMBER 2016
}
An electronic version of the paper may be downloaded
- from the SSRN website: Www.SSRN.com
- from the RePEc website: Www.RePEc.org
- from the CESifo website: www.CESifo-group.org/wp




\title{
Taxation in Digital Media Markets
}

\begin{abstract}
Digital media goods and digital media platforms exhibit cost structures and network effects that imply that price and quantity effects of consumption taxes are qualitatively different compared to what we typically find for physical goods. For instance, in most European countries and US states, printed newspapers and books face favourable value-added taxes (VAT) or sales taxes. This has probably increased their circulation. However, reducing the VAT rate on digital newspapers has the opposite effects; it increases prices and leads to lower sales. This is not true for ebooks, but a low-tax policy is still ineffective if the aim is to reduce prices. The primary effect of exempting such product from value-added taxes is to increase profits for publishers.
\end{abstract}

JEL-Codes: D430, H210, H220, L130.

Keywords: e-books, two-sided markets, media market, pricing strategy, preferential taxation, advertising, public policy.

Hans Jarle Kind Norwegian School of Economics Helleveien 30

Norway - 5045 Bergen

hans.kind@nhh.no
Marko Koethenbuerger

ETH Zurich

Leonhardstrasse 21

Switzerland - 8092 Zurich

koethenbuerger@kof.ethz.ch 


\section{Introduction}

The purpose of this article is to explore how the digitalization process affects optimal taxation policies, and our main focus is on value added taxes (VAT). VAT in general extends to transactions that involve digital goods and services that are traded via digital platforms. The increasing importance of services provided by

digital platforms like Google, Facebook, and YouTube exemplifies the value that digitalization creates in the economy. Similarly, the sale of digital and non-digital goods via platforms like Amazon and Apple has experienced tremendous growth over the last decade.

The provision of digital products and the use of digital platforms have certain characteristics that set them apart from conventional transactions. First, the cost of producing the first unit of a digital good might be substantial, but the creation of an additional copy of digital newspapers or ebooks does not incur any costs. The marginal cost of production and distribution is zero. Second, the point of sale of digital products is geographically highly mobile. Platform infrastructure can be moved across jurisdictions at low cost, akin to a footloose industry. Third, digital platforms are frequently two-sided in nature. Their revenues critically depend on the extent to which they can successfully link different groups of customers. For instance, Google links internet users with advertisers. Users consume the Google search service, and advertisers contact these users through ads for which Google charges a price. The critical aspect of the business model is to manage intergroup network effects. In the context of Google, the price advertisers are willing to pay is increasing in the number of users, while users might well perceive more advertising as a nuisance and shy away when advertising becomes excessive.

Albeit these characteristics appear to be a conventional description of the digital economy, they might have quite non-conventional implications for the evaluation of taxes and the design of optimal tax policies. In this article, we discuss these implications and relate them to actual as well as proposed tax policies in the European 
Union (EU) and the US. We start out by analyzing the book market, accounting for the interdependence between digital and printed books. Interestingly, printed books enjoy a preferential tax treatment in most countries. The same does not hold for ebooks. Although the asymmetric treatment might be argued to put ebooks at a disadvantage, it is not necessarily optimal to reduce the tax rate. ${ }^{1}$ Given the innate characteristic of ebooks that their marginal cost is zero, a lower VAT rate on ebooks generates windfall revenues to the publishers, with little effect on prices and output. That would be close to prescription of an ineffective tax policy if politicians want lower book prices. As far as we know, this has not been formally analyzed previously.

We also look at the tax treatment of goods sold by digital two-sided platforms. As argued above, these platforms are central to the digital economy, and they feature intergroup network externalities. In unraveling the different channels through which these externalities operate and influence tax policy, we also revisit models of a twosided platform that analyze the effects of both value-added and specific taxes. One central finding is that lowering value-added taxes might have the rather surprising effect of reducing output. This has implications for the question of whether newspapers on the web and other digital media products (like TV programs) should enjoy preferential tax treatment. A tax reduction has the presumably unintended effect of decreasing circulation. Thus, the current initiative in some EU countries to set the VAT rate on digital newspapers equal to zero is counterproductive if politicians aim at increasing newspaper circulation.

With the rise of digital platforms and the extended use of personalized advertising, advertising income has become the dominant source of income for many platforms. Digital platforms are highly mobile and platforms such as Google are recurrently accused of tax aggressiveness by locating advertising income in low-tax

\footnotetext{
${ }^{1}$ The differential tax treatment is argued to be conducive to the low market share ebooks have in many countries. See Wischenbart and Celaya (2014) for a documentation of the evolution of the ebook market.
} 
jurisdictions. A higher source-based tax on advertising income (frequently referred to as a Google tax) might be advocated on grounds that such a tax increases welfare in the country in which the tax is levied. Against the background of our model, such a conclusion appears dubious. A higher tax on advertising income not only shifts tax revenues across jurisdictions, but might also reduce consumer surplus in the jurisdiction in which the tax is levied.

All in all, the innate characteristics of digital products and digital platforms (such as zero marginal cost and intergroup network externalities) modify the effects and the optimal design of taxes in potentially unexpected ways. The issue of taxation in the digital economy is frequently discussed in the policy sphere, however without explicitly taking these features into account. ${ }^{2}$ Differently, the peculiarities of digital multi-sided platforms are well analyzed in the scholarly literature (see Caillaud and Jullien, 2003; Anderson and Coate, 2005; Armstrong, 2006; and Rochet and Tirole, 2006, for instance). Contributions by Kind et al. (2008, 2009b, 2010) analyze the role of taxes in two-sided markets. ${ }^{3}$ In the present paper we recapitulate the results from this literature, and we offer some new insight. To this end we first provide a detailed treatment of unconventional quantity responses that arise when the taxed good generates negative intergroup spillovers, such as advertising. We also extend the existing literature to show that even if consumers dislike ads, they might be

\footnotetext{
${ }^{2}$ For instance, Goldfarb et al. (2015) discuss economic issues of the digital economy including government policy, but leave tax policy issues aside. Differently, the report of the European Commission expert group on taxation of the digital economy (European Commission, 2014) particularly emphasizes the international dimensions of taxation, but leaves e.g. network externalities and cost implications unaddressed. Also, in discussions of extending the preferential tax treatment to digital news services in Norway the specific features of digital products are not accounted for which leads to policy views on the effects of taxes that are difficult to reconcile with our analysis, see EFTA Surveillance Authority (2016). We relegate a more in depth discussion of this report to Section 3 .

${ }^{3}$ Issues of tax enforcement that exist with digital sales or, more generally, with e-commerce are discussed in, e.g. Agrawal and Fox (2016) and remain unaddressed in this paper. See also Foros et al. (2014) for a broader discussion of provision of digital goods.
} 
negatively affected by a tax that reduces ad levels. Subsequently, we relate the extended set of insights to actual policy discussions. We contrast the discussions with results on the incidence of the tax and with policy recommendations on how to choose tax policy from an efficiency perspective. These recommendations apply to national tax policies as well as to issues of how to tax digital goods and digital platforms in an international context, as being high on the agenda in the EU and the US.

The paper proceeds as follows. In the first part, we set up a model of an ebook market and analyze the role of taxes both when an ebook supplier competes with a supplier of printed books and when one firm supplies both book formats. We then turn to an analysis of taxes in two-sided platforms. We illustrate the findings in the context of a two-sided media platform and relate them to current discussions on the tax treatment of newspapers and advertising income in various countries, including the issue of taxing digital platforms such as Google in fiscal competition.

\section{The book market}

In this section we set up a simple model of the book market, and we successively modify the model so as to capture different aspects of an efficient taxation. Our main focus will be on value-added taxes (VAT). For this reason we will not consider entry decisions or the variety of titles available in the market, since the VAT policy at best is an inappropriate tool to affect such variables.

Consumers have a quasi-linear utility function of the form $u=\phi\left(x_{1}, x_{2}\right)+m$, where $x_{1}$ and $x_{2}$ are consumption of printed and digital books, respectively, and $m \gtreqless 0$ is the numéraire good. ${ }^{4}$ The utility function $\phi\left(x_{1}, x_{2}\right)$ satisfies all the usual conditions for utility maximization, in particular that $\partial \phi / \partial x_{i} \equiv \phi_{x_{i}}>0$ and $\partial^{2} \phi / \partial x_{i}^{2} \equiv \phi_{x_{i} x_{i}}<0, i=1,2$. In what follows we use subscripts to denote partial derivatives and, for ease of exposition, we suppress the fact that $i, j=1,2$

\footnotetext{
${ }^{4}$ In order to abstract from corner solutions in demand choices, we allow $m$ to become negative.
} 
and $i \neq j$. We assume that printed and digital books are weak substitutes, i.e. $\phi_{x_{i} x_{j}} \leq 0$. The budget constraint is $I=m+\sum_{i} p_{i} x_{i}$ where $I$ is income and $p_{i}$ is the price of good $i$.

Utility maximization yields consumer demand $x_{i}=x_{i}\left(p_{1}, p_{2}\right)$, with $\partial x_{i} / \partial p_{i}<0$ and $\partial x_{i} / \partial p_{j} \geq 0$. The two goods are substitutes in consumption if $\partial x_{i} / \partial p_{j}>0$ and unrelated if $\partial x_{i} / \partial p_{j}=0$. This is the case if $\phi_{x_{i} x_{j}}=0$.

The marginal cost of producing and distributing printed books is $c_{1}>0$. It is an innate characteristic of digital products that the marginal production cost is zero, so we set $c_{2}=0$.

\subsection{The social optimum}

A social planner chooses output so as to maximize the sum of consumer utility and firm profit minus the costs of providing the two goods. We thus solve (first-best allocations are marked by $\left.{ }^{*}\right)$ :

$$
\left\{x_{1}^{*}, x_{2}^{*}\right\}=\arg \max _{\left\{x_{1}, x_{2}\right\}}\left\{\phi\left(x_{1}, x_{2}\right)-c_{1} x_{1}\right\}
$$

This yields the first-order conditions

$$
\phi_{x_{1}}\left(x_{1}^{*}, x_{2}^{*}\right)=c_{1} \text { and } \phi_{x_{2}}\left(x_{1}^{*}, x_{2}^{*}\right)=0
$$

which simply says that the socially optimal output levels are such that the marginal willingness to pay equals the marginal cost of production.

\subsection{Competition between providers of printed and digital books}

A firm like Apple specializes in ebooks, while many bookstores specialize in printed books. So, suppose that firm 1 only sells printed books and firm 2 only sells ebooks. Then profits for firm $i=1,2$ equals

$$
\pi_{i}=\frac{p_{i}}{1+\tau_{i}} x_{i}-c_{i} x_{i}
$$


where $\tau_{i}$ is the ad-valorem tax that is levied on sales of commodity $x_{i}{ }^{5}$ Solving $d \pi_{1} / d p_{1}=0$ we find that the first-order condition for printed books is

$$
\frac{1}{1+\tau_{1}}\left[x_{1}\left(p_{1}, p_{2}\right)+p_{1} \frac{d x_{1}}{d p_{1}}\right]-c_{1} \frac{d x_{1}}{d p_{1}}=0,
$$

which implies that the price of printed books is increasing in own VAT rate. Throughout, we assume that the second-order conditions are satisfied.

For digital books we have

$$
\frac{1}{1+\tau_{2}}\left[x_{2}\left(p_{1}, p_{2}\right)+p_{2} \frac{d x_{2}}{d p_{2}}\right]=0 .
$$

Equation (3) makes it clear that the VAT rate on ebooks acts like a pure profit tax. Changing the VAT rate on digital books thus has no effect on the equilibrium price, and consequently no efficiency implications. The fact that value-added taxes at the outset affect equilibrium prices only for goods with positive marginal costs is apparently often overlooked in public debates.

Lemma 1: Suppose that printed and digital books are supplied by different firms. The VAT rate on digital books has no quantity effect. A uniform tax treatment of the two book formats is not warranted based on efficiency grounds.

If the markets for printed and digital books are completely separated (independent in demand), the VAT rate on printed books has no effect on sales of digital

\footnotetext{
${ }^{5}$ As pointed out by one of the referees, retailers may in principle have to pay positive wholesale prices for ebooks even though marginal production and distribution costs are equal to zero. However, pure revenue-sharing has become the dominant business model for ebooks (see, e.g., ebookarchitects.com and http://www.slideshare.net/eBOUNDCanada/wholesale-vs-agency-deck ). Apple and Amazon, for instance, are not charged any unit fees by the publishers for books; instead the publishers keep $70 \%$ of the sales revenue the books generate. It therefore seems like a reasonable approximation to assume that marginal costs for sellers of ebooks are zero. See also Foros et al. (2014) for a further discussion of the widespread use of pure revenue-sharing in the market for digital goods. This being said, an interesting extension of the model could be to see how wholesale tariffs and the organization of the vertical value chain might depend on tax policy. We leave this for future research.
} 
books. However, more realistically the two markets are related, in which case firstorder conditions (2) and (3) define the best response functions $\hat{p_{1}}\left(p_{2}, \tau_{1}\right)$ and $\hat{p_{2}}\left(p_{1}\right)$. Prices are strategic complements $\left(d p_{i} / d p_{j}>0\right)$ if the two book formats are (imperfect) substitutes and $d^{2} x_{i} / d p_{i} d p_{j}$ is not too negative (i.e., if a higher price $p_{i}$ either amplifies or only has a slightly moderating effect on the positive cross price effect $\left.d x_{i} / d p_{j}\right)$. It then follows that, since $p_{1}$ is increasing in $\tau_{1}$, the same is true for $p_{2}$. In other words, the VAT rate on printed books spills over to the ebook market through the best response functions.

From first-order conditions (2) and (3) it follows that the market equilibrium satisfies

$$
\phi_{x_{1}}>c_{1} \text { and } \phi_{x_{2}}>0
$$

Comparing with the social optimum, equation (1), the market outcome is inefficient because price is higher than marginal costs. Thus, defining welfare $W$ as the sum of consumer surplus, firm profit and tax revenues, a higher tax rate $\tau_{1}$ increases welfare if $f^{6}$

$$
\frac{d W}{d \tau_{1}}=\left(\phi_{x_{1}}-c_{1}\right) \frac{d x_{1}}{d \tau_{1}}+\phi_{x_{2}} \frac{d x_{2}}{d \tau_{1}}>0 .
$$

It is important to bear in mind that even with prices being strategic complements, we have $d x_{1} / d \tau_{1}<0$ and $d x_{2} / d \tau_{1}>0$. Fixing $p_{2}$, a higher tax $\tau_{1}$ reduces the quantity $x_{1}$ and increases the price $p_{1}$. This in turn increases $x_{2}$, the demand for ebooks. The general equilibrium adjustment in $p_{2}$ is of second order, and will not neutralize the demand effects. An increase in $\tau_{1}$ thus increases the distortion in the market for printed books and reduces the distortion in the ebook market. Suggestively, the welfare effect is positive when the marginal utility from consuming $x_{2}$ is sufficiently high compared to the marginal utility from consuming $x_{1}$. In this case, a higher tax on printed books shifts book consumption to ebooks, a positive effect which is then higher valued by customers than the loss in consumption of printed books.

\footnotetext{
${ }^{6}$ It is worth pointing out that efficiency can be preserved for any distribution of the tax revenue among consumers. This is due to the quasi-linearity of the preferences.
} 
We resort to a specific consumer demand function to illustrate the effect of taxes.

Example 1: Assume the preference term $\phi\left(x_{1}, x_{2}\right)$ takes the Shubik Levitan form $^{7}$

$$
\phi\left(x_{1}, x_{2}\right)=\alpha_{1} x_{1}+\alpha_{2} x_{2}-\left[(1-s)\left(x_{1}^{2}+x_{2}^{2}\right)+\frac{s}{2}\left(x_{1}+x_{2}\right)^{2}\right] .
$$

The parameter $s \in[0,1)$ measures the degree of substitutability between printed and digital books. In the limit $s \rightarrow 1$ the two types of books are perfect substitutes, while they are independent in demand if $s=0$. The preference parameter $\alpha_{i}>0$ is assumed to be sufficiently large for marginal utility to become positive over the relevant range for both goods.

Utility maximization implies that the demand functions for $x_{1}$ and $x_{2}$ are

$$
x_{i}=\frac{(2-s)\left(\alpha_{i}-p_{i}\right)+s\left(p_{j}-\alpha_{j}\right)}{4(1-s)} .
$$

A higher degree of substitutability $s$ increases the cross-price effect $\partial x_{i} / \partial p_{j}$ and, as a mirror image, magnifies the negative own-price response $\partial x_{i} / \partial p_{i}$. Since $\partial^{2} \pi_{i} / \partial p_{i} \partial p_{j}=$ $s /\left[4\left(1+\tau_{i}\right)(1-s)\right]>0$ and $\partial^{2} \pi_{i} / \partial p_{i}^{2}=-(2-s) /\left[4\left(1+\tau_{i}\right)(1-s)\right]<0$, it follows that prices are strategic complements; $d p_{i} / d p_{j}>0$ for $s>0$.

Solving $\partial \pi_{i} / \partial p_{i}=0$ for the two firms and then differentiating prices w.r.t. $\tau_{1}$ yields

$$
\begin{aligned}
& \frac{d p_{1}}{d \tau_{1}}=\frac{2(2-s)^{2}}{(4-3 s)(4-s)} c_{1}>0 \\
& \frac{d p_{2}}{d \tau_{1}}=\frac{s}{2(2-s)} \frac{d p_{1}}{d \tau_{1}} \geq 0
\end{aligned}
$$

In this simple model the welfare effect (4) is positive only if $\alpha_{2} \gg \alpha_{1}$, i.e. when the marginal utility of consuming $x_{2}$ is sufficiently higher than the marginal utility of consuming $x_{1}{ }^{8}$

\footnotetext{
${ }^{7}$ We could also have used e.g. a standard quadratic utility function. This would not have affected the qualitative results. However, an advantage of using Shubik Levitan is that market size does not vary with the parameter that measures substitutability among goods.

${ }^{8}$ Note, $d x_{1} / d \tau_{1}$ and $d x_{2} / d \tau_{1}$ are independent of $\alpha_{i}$. From (5), $\alpha_{i}$ thus independently magnifies $\phi_{x_{i}}$ which renders the welfare effect of a higher tax $\tau_{1}$ to be positive when $\alpha_{2} \gg \alpha_{1}$.
} 
In Figure 1, where we measure the substitutability between the two book formats on the horizontal axis, we illustrate the welfare effects of a small increase in $\tau_{1}$ from $\tau_{1}=0 .{ }^{9}$ If printed and digital books are poor substitutes, a higher VAT rate on printed books will reduce sales of printed books, but mainly leave sales of digital books unchanged. The welfare effect is therefore negative. However, the closer substitutes the formats are, the more will sales of digital books increase as a response to a higher $\tau_{1}$, and if $s>0.55$ we have that $d W / d \tau_{1}>0$. If consumers over time to a greater and greater extent are willing to shift from printed to digital books, the welfare consequences of a higher VAT on printed books might be only slightly negative, or even positive.

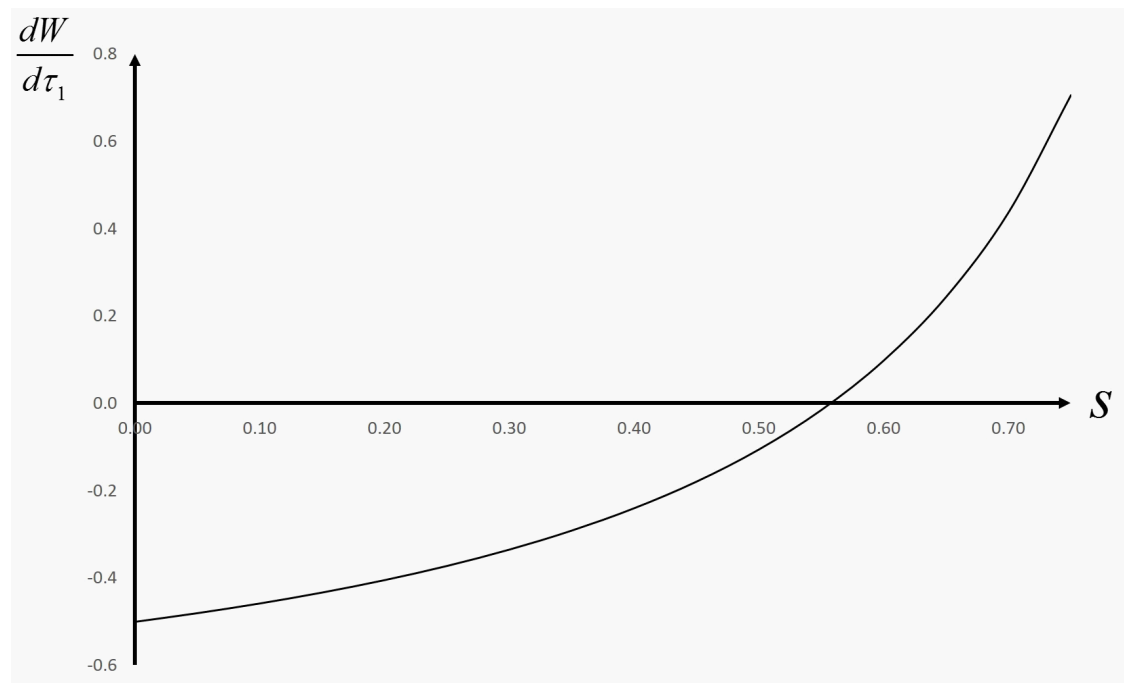

Figure 1: Welfare effects of increasing the VAT rate on printed books.

Printed books receive a preferential ad valorem tax treatment in most countries; it is significantly lower than the regular VAT or even set to zero. Books are considered to be a vital source of cultural values and education whose consumption shall be promoted by levying a reduced VAT rate. While the positive effect of a lower $\tau_{1}$ on $x_{1}$ tends to serve this goal, it is arguably the effect on total consumption levels $x_{1}+x_{2}$ that is the relevant metric for judging the appropriateness of the tax policy. For the paternalistic goal of fostering cultural values, the book format (printed book

\footnotetext{
${ }^{9}$ The parameter values that underly Figure 1 are $\tau_{1}=0, c_{1}=1, \alpha_{1}=5$ and $\alpha_{2}=10$.
} 
vs. ebook) is of second order, or of no relevance. From that perspective, the low paper tax creates some leakage effect by reducing consumption of digital books, and has lost some effectiveness in fostering consumption of books. Interestingly, the preferential tax treatment is not extended to ebooks in most countries. This might be a reasonable strategy according to the results above.

We shall now see that an effective tax instrument to stimulate sales of ebooks is to levy a negative unit tax on ebooks. With a unit tax $t_{2}$, the first-order condition for $p_{2}$ is

$$
x_{2}\left(p_{1}, p_{2}\right)+\left(p_{2}-t_{2}\right) \frac{d x_{2}}{d p_{2}}=0 .
$$

The tax $t_{2}$ serves as a marginal cost of providing ebooks with the consequence of influencing $x_{2}$ and, through its effect on prices, also $x_{1}$. With two taxes that influence consumption of books, the social optimum can be implemented. Using (2) and (8), the optimal unit tax rate $t_{2}$ and ad-valorem $\operatorname{tax} \tau_{1}$ are

$$
t_{2}^{*}=\frac{x_{2}^{*}\left(p_{1}, p_{2}\right)}{\frac{d x_{2}^{*}}{d p_{2}}}<0 \quad \text { and } \quad \tau_{1}^{*}=\frac{x_{1}^{*}\left(p_{1}, p_{2}\right)}{c_{1} \frac{d x_{1}^{*}}{d p_{1}}}<0 .
$$

A preferential tax treatment of both book formats thus unambiguously promotes total consumption when we open up for (negative) unit taxes on digital books. The unit tax consequently allows the government to raise efficiency compared to a situation with ad-valorem taxes only (and might be beneficial from a paternalistic point of view). This being said, VAT taxes are clearly easier to implement and administer.

We can state:

Proposition 1: Suppose that printed and digital books are supplied by different firms. A higher ad valorem tax on printed books reduces sales of printed books and increases sales of digital books.

(i) Assume that only ad valorem taxes are available. Then, social optimum is not achievable. It is efficient to impose a positive ad valorem tax on printed books $\left(\tau_{1}^{*}>0\right)$ provided that this leads to a sufficiently large increase in sales of digital books. 
(ii) Assume that both ad valorem and unit taxes are available. Social optimum can then be achieved by imposing a negative VAT rate on printed books $\left(\tau_{1}^{*}<0\right)$ and a negative unit tax $\left(t_{2}^{*}<0\right)$ on digital books.

The tax treatment of ebooks also has an international dimension. Before 2015, digital products sold online were subject to the VAT in the country of the seller (as of 2015 the place of taxation will be determined by the location of the consumer). ${ }^{10}$ Tax competition led to a reduction in VAT for digital products in some countries. For instance, Luxembourg offered a reduced source-based VAT rate on digital products (in addition to a favorable tax treatment of corporate profits), which implied that a significant amount of on-line sales was done by sellers located in Luxembourg. Online platforms like Amazon, Google, or Apple decided to set headquarters in Luxembourg, where a particularly low VAT rate of $3 \%$ was offered for ebooks (as well as for printed books). ${ }^{11}$ Against the background of the simple analysis above, a low tax burden on digital books has no quantity or price effects for consumers. This indicates that the tax competition for sellers of digital products has mainly been a windfall gain to these firms.

In the model we leave out tax revenue constraints for the government and focus on the issue of corrective taxation. With a tax revenue constraint, optimal taxes serve two purposes. They finance a given amount of tax revenues with a minimum distortionary loss (so-called Ramsey tax problem) and, at the same time, are used to correct inefficiencies due to market failures. In this situation, the optimal level of taxes tends to be upwardly adjusted just to satisfy the revenue requirement. ${ }^{12}$

\footnotetext{
${ }^{10}$ This is in line with the destination principle that is the dominant form of commodity taxation in the EU. See Lockwood (2001) for a more in-depth analysis of commodity tax principles.

${ }^{11}$ Possibly being an outcome of fiscal competition, the reduced tax rate for ebooks (the standard VAT rate was $15 \%$ in Luxembourg) was conducive to the location decision of online platforms, but was not covered by the European Union's VAT Directive (Directive 2006/112/EC). The directive has not allowed VAT to be lowered on ebooks. In response, the EU referred Luxembourg to the Court of Justice over reduced VAT rates on ebooks (EU Press Release, IP/13/137).

${ }^{12}$ The reasoning is related to Sandmo's (1975) 'additivity property' which characterizes optimal
} 
We abstain from formally characterizing these tax rates. This serves to highlight the forces that justify positive or negative taxes to correct market failures in digital media markets and that are different to traditional markets. Interestingly, in this section, the optimal taxes characterized above might stay intact in the presence of a tax revenue requirement. This is due to the fact that the tax on ebooks $\tau_{2}$ is a lump-sum tax and will be used by the government to collect the required amount of tax revenues, provided the non-negativity constraint for profits $\pi_{2} \geq 0$ is not violated. This holds when the government is restricted to an ad-valorem $\operatorname{tax} \tau_{1}$ and when it uses a combination of an ad-valorem $\operatorname{tax} \tau_{1}$ and a unit taxes $t_{2}$ to correct market failures.

\subsection{The same publisher sells printed books and ebooks}

In most cases a publisher has monopoly rights over any given book title. For instance, when Jo Nesbø comes with a new book, the publisher might not be too concerned with competition between Nesbø's new book and other book titles. However, tax policies and other factors could make it more profitable to sell a printed version than a digital version of Nesbø's new novel (or vice versa). The publisher might therefore be quite concerned about the relative sales of the two book formats. As the converse extreme of the example above, assume therefore that the two goods we consider are sold by one and the same firm. This firm will then solve the following maximization problem:

$$
\max _{\left\{p_{1}, p_{2}\right\}}\left\{\pi_{1}+\pi_{2}\right\}
$$

(Ramsey and corrective) taxes in a setting with consumption externalities as a source of policy intervention. Tax formulae are composed of a Ramsey part and a corrective part which tends to increase the overall optimal tax above the corrective tax. See also Sadka (1978) and Ng (1980) for related analyses. 
Given demands for printed and digital books, $x_{i}\left(p_{1}, p_{2}\right), i=1,2$, the first-order condition for $p_{1}$ is

$$
\frac{1}{1+\tau_{1}}\left[x_{1}\left(p_{1}, p_{2}\right)+p_{1} \frac{d x_{1}}{d p_{1}}\right]-c_{1} \frac{d x_{1}}{d p_{1}}+\frac{p_{2}}{1+\tau_{2}} \frac{d x_{2}}{d p_{1}}=0 .
$$

Compared to the first-order condition in the previous section, the last term on the left-hand side of $(10)$ is new. This term captures the fact that the firm internalizes the interdependency between the market for printed and digital books. A higher price $p_{1}$ shifts sales to the ebook market.

The first-order condition for $p_{2}$ is similarly

$$
\frac{1}{1+\tau_{2}}\left[x_{2}\left(p_{1}, p_{2}\right)+p_{2} \frac{d x_{2}}{d p_{2}}\right]+\frac{p_{1}}{1+\tau_{1}} \frac{d x_{1}}{d p_{2}}=0
$$

First-order condition (11) reveals that the $\operatorname{tax} \tau_{2}$ on ebooks is not neutral for the pricing decision of the firm (unless $\tau_{1}=\tau_{2}$ ). The firm has an incentive to shift demand away from the ebook market to the market for printed books by raising the price for ebooks if $\tau_{2}$ increases. At the optimum, the marginal ebook revenues remain positive although marginal production costs are zero, i.e. $c_{2}=0$. The loss in revenues from selling printed books effectively serves as a marginal cost of selling ebooks.

Straightforwardly, from (1) the two book quantities are not socially optimal. A higher tax rate $\tau_{i}$ increases welfare provided

$$
\left(\phi_{x_{1}}-c_{1}\right) \frac{d x_{1}}{d \tau_{i}}+\phi_{x_{2}} \frac{d x_{2}}{d \tau_{i}}>0
$$

For instance, a higher tax rate $\tau_{1}$ aggravates the inefficiency in the market for printed books while generically lowering the inefficiency in the market for ebooks. Now the government has two tax instruments at its disposal to resolve the trade-off. Setting the term in (12) to zero and using (10) and (11), the optimal choice of tax rates is

$$
\tau_{i}^{*}=\frac{\left(p_{j}^{*}+x_{j}^{*} d p_{j}^{*} / d x_{j}\right)\left(x_{i}^{*} d p_{i}^{*} / d x_{i}\right)-x_{j}^{*} d p_{j}^{*} / d x_{i}\left(x_{j}^{*} d p_{j}^{*} / d x_{j}\right)}{\left(p_{j}^{*}+x_{j}^{*} d p_{j}^{*} / d x_{j}\right) c_{i}-x_{j}^{*} d p_{j}^{*} / d x_{i} c_{j}}<0 .
$$


From (10) and (11), the optimal tax rates are negative. Since books are undersupplied in non-competitive markets, a subsidy on both book formats raises welfare through higher output.

The optimal tax policy entails a favorable tax treatment of printed books and ebooks. The degree to which this is warranted might however differ across the two book formats. A uniform subsidy is not optimal. This is not because uniformity of tax policies is in general only a knife-edge outcome in optimal commodity tax problems (Auerbach and Hines, 2002). The reason is that a uniform subsidy leaves the incentive to price ebooks unchanged, thereby providing only one instrument to the policy maker to correct two distortions. Strikingly, different ad-valorem taxes are thus necessarily part of a first-best tax policy in this environment.

We can therefore summarize:

Proposition 2: Suppose that the same firm sells both printed and digital books. Social optimum can then be achieved through setting negative ad valorem taxes on the two books formats $\left(\tau_{i}^{*}<0, i=1,2\right)$. In general, a non-uniform tax treatment is optimal $\left(\tau_{1} \neq \tau_{2}\right)$.

\section{Digital two-sided media markets}

In the digital economy, an increasing number of transactions are mediated through electronic platforms. Many platforms are multi-sided, in the sense that they have two or more different groups of customers that they derive income from. Media firms (TV, Radio, newspapers, magazines, and web portals) is an example of a multi-sided industry. A newspaper, for instance, has at least two distinct groups of customers; readers and advertisers. Readers derive a direct benefit from consuming the media product, whilst advertisers derive an indirect benefit from contacting potential customers from the group of readers. Other examples of multi-sided platforms are payment cards (merchants and cardholders), dating clubs (men and women), and operating system software (application developers and users). 
A very interesting feature of multi-sided platform industries is that their pricing strategies must account for interactions between the demands of multiple customer groups, and that pricing must reflect the externalities that arise in these relationships (Rochet and Tirole, 2003). ${ }^{13}$ Below, we present a simple model to show that these externalities might quantitatively and qualitatively change how VAT and specific taxes work compared to similar taxes in traditional (one-sided) markets.

In contrast to Section 2, we now consider a setting with two different groups of customers that are served by a platform. A (representative) consumer of group $i$ $(i=1,2)$ has a quasi-linear utility function of the form

$$
u^{i}=m^{i}+\phi^{i}\left(x^{i}, x^{j}\right), \quad i, j=1,2 \quad \text { and } \quad i \neq j
$$

where $m^{i} \gtreqless 0$ is consumption of the outside good (the numéraire good). ${ }^{14}$ The utility function $\phi^{i}\left(x^{i}, x^{j}\right)$ is increasing in the units of the good the consumer buys from the platform, $x^{i}$, at a decreasing rate; $\phi_{x^{i}}^{i}>0$ and $\phi_{x^{i} x^{i}}^{i}<0$. Intergroup externalities are captured by the cross derivative $\phi_{x^{j}}^{i}$, and might be positive or negative. ${ }^{15}$ It is positive $\left(\phi_{x^{j}}^{i}>0\right)$ if higher output of good $j$ increases the willingness to pay for good $i$, while it is negative $\left(\phi_{x^{j}}^{i}<0\right)$ if the opposite is true. In order to have a two sided market, there must be positive externalities from at least one side of the market to the other. ${ }^{16}$ The implication of this is that $\partial p^{i} / \partial x^{j}>0$ for at least one $\operatorname{good}^{17}$

Straightforwardly, maximization of the utility function subject to the budget

\footnotetext{
${ }^{13}$ Recent contributions in the context of media markets include Ambrus et al. (2016), Athey et
} al. (2016) and Anderson et al. (2016a).

${ }^{14}$ As before, we allow for $m^{i}<0$ so that we do not have to consider corner solutions.

${ }^{15}$ Intergroup externalities are frequently referred to as indirect network effects. In the model we abstract from direct network effects, i.e. customers do not care about the number of agents on their own side.

${ }^{16}$ Intuitively, when $\phi_{x^{j}}^{i}<0$ for both sides of the platform, the platform is not able to create value by linking the two groups. This inherent feature of two-sided markets is important for the evaluation and design of tax policies in two-sided markets, as shown below.

${ }^{17}$ The intergroup demand interdependencies should not be confused with standard theory of complements or substitutes, as analyzed in the previous section. For instance, in the two-sided market 
constraint for each group $\omega^{i}=m^{i}+p^{i} x^{i}$ yields the inverse demand function for good $i$ :

$$
p^{i}\left(x^{i}, x^{j}\right)=\phi_{x^{i}}^{i}\left(x^{i}, x^{j}\right)
$$

In the context of a newspaper (which we will use as our working example), the two groups of customers are readers (group 1) and advertisers (group 2). The representative reader receives utility from consuming $x^{1}$ units of newspapers with $x^{2}$ units of ads. Similarly, for advertisers a representative firm receives utility from posting $x^{2}$ units of ads in the newspaper. In order to capture essential features of the media market, we shall assume that the willingness to pay for an ad is increasing in the number of newspapers sold; $\phi_{x^{1}}^{2}>0$ and thus $\partial p^{2} / \partial x^{1} \equiv p_{x^{1}}^{2}\left(x^{1}, x^{2}\right)>0$.

The profit of the media platform equals

$$
\pi=\sum_{i=1}^{2} \frac{p^{i} x^{i}}{1+\tau^{i}}-C\left(x^{i}, x^{j}\right)
$$

where $\tau^{i} \gtreqless 0$ is the ad valorem tax on good $i$. The cost function $C\left(x^{i}, x^{j}\right) \geq 0$ satisfies $C_{x^{i}} \geq 0$ and $C_{x^{i} x^{i}} \geq 0$. For instance, for electronic communications services such as internet newspapers $C_{x^{1}}=0$ is particularly likely. Differently, for printed newspapers we have $C_{x^{1}}>0$.

\subsection{The social optimum}

To unravel the welfare implications of taxes in two-sided media markets it is instructive to characterize the social optimum first. A social planner chooses output so as to maximize the sum of consumer surplus plus platform profits. This amounts to solving

$$
\left\{x^{1 *}, x^{2 *}\right\}=\arg \max _{\left\{x^{1}, x^{2}\right\}}\left\{\sum_{i=1}^{2} \phi^{i}\left(x^{i}, x^{j}\right)-C\left(x^{1}, x^{2}\right)\right\} .
$$

there is no guarantee that the demand interdependencies are fully accounted for by the platform's pricing decision, different to demand interdependencies due to complements or substitutes. This is due to the fact that the platform serves two different groups of customers, whereas the effects of complementarity or substitutability in demand are 'internal' to consumers and reflected in the pricing decision of firms. 
Given that the second-order conditions for interior solutions hold, the socially optimal quantities (marked by ${ }^{*}$ ) satisfy

$$
p^{i *}=C_{x^{i}}\left(x^{i *}, x^{j *}\right)-\phi_{x^{i}}^{j}\left(x^{i *}, x^{j *}\right) .
$$

Prices should be set equal to marginal costs corrected for the marginal social spillover to the other side of the platform, as measured by $\phi_{x^{i}}^{j}\left(x^{i *}, x^{j *}\right)$. The last term is unique to a two-sided platform and, for instance, does not arise in the context of product complementarity. In the latter case, any change in the evaluation of complementary products is internal to the consumer and fully reflected by the inverse demand function.

\subsection{Market equilibrium}

As a simplification, we consider a monopoly media platform. This allows us to ignore strategic interaction between different media firms. ${ }^{18}$ To find the market equilibrium, we differentiate (15) w.r.t. $x^{1}$ and $x^{2}$. Using (14) and (15), the media platform's first-order conditions are: ${ }^{19}$

$$
\frac{p^{i}\left(x^{i}, x^{j}\right)+x^{i} p_{x^{i}}^{i}\left(x^{i}, x^{j}\right)}{1+\tau^{i}}=C_{x^{i}}\left(x^{i}, x^{j}\right)-\frac{x^{j} p_{x^{i}}^{j}\left(x^{i}, x^{j}\right)}{1+\tau^{j}}
$$

Two terms in (17) reflect the inefficiency of the platform's choices. First, due to the price-setting power, the monopolist accounts for the drop in the price and thus revenues when selling one extra unit of good $i$. This is reflected by the term $x^{i} p_{x^{i}}^{i}\left(x^{i}, x^{j}\right)$ on the left-hand side of equation (17). Taken in isolation, the price will be set above marginal costs, which implies underprovision of commodity $i$.

\footnotetext{
${ }^{18}$ The basic findings hold also in the presence of imperfect competition. See Kind et al. (2009a, 2010).

${ }^{19}$ The second-order conditions require

$$
H=\pi_{x^{1} x^{1}} \pi_{x^{2} x^{2}}-\left(\pi_{x^{1} x^{2}}\right)^{2}>0, \quad \pi_{x^{1} x^{1}}<0 \text { and } \pi_{x^{2} x^{2}}<0 .
$$
}


The second source of inefficiency is due to the potentially inappropriate pricing of intergroup externalities. Selling one extra unit of good $i$ increases the willingness to pay for good $j$ by $p_{x^{i}}^{j}\left(x^{i}, x^{j}\right)$ units. The resulting extra income $x^{j} p_{x^{i}}^{j}\left(x^{i}, x^{j}\right)$ enters the first-order condition (17) on the right-hand side. Relevant for the effects of taxes, the term acts like a marginal cost shifter. It reduces the 'effective' marginal costs of producing good $i$ if $p_{x^{i}}^{j}>0$.

The government can use tax policy to address the inefficiencies. Taking the total differential of the first-order conditions (17) w.r.t. the tax rate $\tau^{i}$ and setting $\tau^{j}=0$ yields:

$$
\begin{gathered}
\frac{d x^{i}}{d \tau^{i}}=\frac{-\pi_{x^{j} x^{j}}\left(x^{j} p_{x^{i}}^{j}-C_{x^{i}}\right)}{H\left(1+\tau^{i}\right)}+\frac{-\pi_{x^{i} x^{j}} x^{i} p_{x^{j}}^{i}}{H\left(1+\tau^{i}\right)^{2}} \\
\frac{d x^{j}}{d \tau^{i}}=\frac{\pi_{x^{i} x^{j}}\left(x^{j} p_{x^{i}}^{j}-C_{x^{i}}\right)}{H\left(1+\tau^{i}\right)}+\frac{\pi_{x^{i} x^{i}} x^{i} p_{x^{j}}^{i}}{H\left(1+\tau^{i}\right)^{2}}
\end{gathered}
$$

From (18), it is straightforward to check that in the absence of two-sidedness $\left(p_{x^{j}}^{i}=p_{x^{i}}^{j}=0\right)$ the tax response would be negative, $d x^{i} / d \tau^{i}<0$. Interestingly, we will now see that this need not be the case when we have a two-sided market. The first-order conditions (18) and (19) may imply that output of good $i$ is increasing in own tax rate (as was first shown in Kind et al., 2008).

\subsubsection{Effects of a tax on newspapers}

Let us now interpret equations (18) and (19). Since the advertiser side values readers, we have $p_{x^{1}}^{2}>0$. For digital goods the marginal cost of providing these goods is small (typically approximately zero). Hence, it is conceivable to assume that $x^{2} p_{x_{1}}^{2}-C_{x^{1}}>0$ holds. Now, assume that the VAT rate on newspaper sales increases $\left(d \tau_{1}>0\right)$. Then the platform would like to shift revenue from the reader side to the advertiser side of the market. This it can do by reducing the price for newspapers; thereby newspaper circulation and thus the willingness to pay for ads increase. To

the extent that the rise in newspaper circulation increases the marginal profitability 
of advertising, $\pi_{x^{1} x^{2}}>0$, and readers are e.g. ad averse, $p_{x^{2}}^{1}<0$, a higher newspaper tax therefore increases newspaper circulation, i.e. $d x^{1} / d \tau^{1}>0 .{ }^{20}$ Note that the number of ads will also increase in response to the tax on newspaper sales, i.e. $d x^{2} / d \tau^{1}>0$.

The finding has important implications for taxation of electronic as well as printed newspapers. In most countries printed newspapers are subject to a reduced value-added tax rate. In Germany it is subject to a rate of $7 \%$ (19\% is the regular rate) while in e.g. the UK and Denmark they are exempted from value-added taxation all together (European Commission, 2016). Newspapers are also either fully or partially exempted from sales taxes in a number of U.S. states. The reason for the preferential tax treatment is that governments consider newspapers to be essential for the dissemination of vital information regarding for instance culture, politics and international affairs. A lower tax rate is thought to reduce the newspaper price and, more importantly, to increase the circulation of the media product. The reasoning is in line with tax incidence analysis in a one-sided market, but the analysis above shows that this need not hold for the newspaper industry, which typically operates in a two-sided market. On the contrary, a lower VAT may reduce the sales of newspapers. This is particularly likely to be true for digital newspapers, since marginal costs are equal to zero. This makes it costless for the newspaper to increase circulation in order to become more attractive in the advertising market.

From equation (18) we see that whether a VAT increases or reduces circulation might depend on the readers' attitude to ads (i.e., whether $p_{x_{2}}^{1}$ is negative or positive). Here the empirical evidence is mixed. Depken II and Wilson (2004), for instance, find that advertising is considered to be a good in some paper magazines and a bad in others. Presumably, we find a similar variety in the public's attitude to advertising also in the newspaper industry. So what can the government do if it wants to spur output of newspapers? A more accurate policy than changing the

\footnotetext{
${ }^{20}$ The positive response equally holds when readers are ad neutral, $p_{x^{2}}^{1}=0$, or are ad loving, $p_{x^{2}}^{1}>0$, but only moderately so.
} 
VAT rate, would be to subsidize newspapers through specific taxation. To see this, let the profit level of the media firm be given by

$$
\pi=\frac{\left(p^{1}-t^{1}\right) x^{1}}{1+\tau^{1}}+p^{2} x^{2}-C\left(x^{1}, x^{2}\right),
$$

where $t^{1}$ is the unit tax on newspapers. The first-order conditions for the platform are the same as before, except that the unit tax now appears as an additional cost term in selling newspapers (c.f. equation (17)):

$$
\frac{p_{x^{1}}^{1} x^{1}+p^{1}}{1+\tau^{1}}+p_{x^{1}}^{2} x^{2}=C_{x^{1}}\left(x^{1}, x^{2}\right)+\frac{t^{1}}{1+\tau^{1}} .
$$

and

$$
p^{2}+x^{2} p_{x^{2}}^{2}+\frac{p_{x^{2}}^{1} x^{1}}{1+\tau^{1}}=C_{x^{2}}\left(x^{1}, x^{2}\right)
$$

Totally differentiating (20) and (21), holding $\tau^{1}$ fixed, we find

$$
\frac{d x^{1}}{d t^{1}}=\frac{\pi_{x^{2} x^{2}}}{\left(1+\tau^{1}\right) H}<0 \text { and } \frac{d x^{2}}{d t^{1}}=-\frac{\pi_{x^{1} x^{2}}}{\left(1+\tau^{1}\right) H} .
$$

Equation (22) makes it clear that a unit tax on a newspaper unambiguously reduces its circulation, independently of consumer preferences for ads. The reason is that higher specific taxes are equivalent to increased unit costs, as shown by equation (20). Since higher unit costs lower the marginal profitability for any given output, it is therefore optimal to reduce sales of newspapers $\left(d x^{1} / d t^{1}<0\right)$. As a result, also the advertising level falls $\left(d x^{2} / d t^{1}<0\right)$ if $\pi_{x^{1} x^{2}}>0$, while it increases if $\pi_{x^{1} x^{2}}<0 .{ }^{21}$

We should note that unit taxes might have an additional virtue in two-sided markets. They might yield higher welfare and tax revenues compared to ad-valorem taxes (Kind et al., 2009b). This is in contrast to a benchmark result in public economics which states that it is possible to increase both tax revenue and welfare by making a monopoly subject to ad valorem taxes rather than unit taxes (Suits and Musgrave, 1953; Delipalla and Keen, 1992).

Since its implementation in 2006, the European Union's VAT Directive (Directive 2006/112/EC) has not allowed VAT to be lowered on digital content. In the

\footnotetext{
${ }^{21} \mathrm{~A}$ more thorough discussion of the sign of $\pi_{x^{1} x^{2}}$ is relegated to Section 3.2.2.
} 
EU, the favorable tax treatment of newspapers thus does not apply to electronic newspapers. In order to level the playing field between the newspaper formats, though, there are discussions on the possibility to extend the preferential taxation to electronic newspapers. ${ }^{22}$ Noteworthy, in January 2016 the EFTA Surveillance Authority (ESA) granted a temporary approval on an application from the Norwegian Government to extend the zero VAT rates to digital news media (inclusive of TV channels that "mainly broadcast a broad range of news"). However, ESA does not seem to take the two-sidedness into account, and conclude that a lower VAT rate on digital newspapers will lead to lower subscription prices and increased circulation. The tax reduction will obviously increase newspaper profits and perhaps entry of digital editions, but the first-order effect will be to increase prices. ${ }^{23}$

\subsubsection{Effects of a tax on advertising revenues}

With the rise of digital platforms and the extended use of e.g. personalized advertising, advertising income has become the dominant source of income for many platforms. Its tax treatment has become a growing concern for platform owners and policy makers alike ${ }^{24}$ To scrutinize on this issue, let us now consider the effect of taxing the advertising side of the platform $(i=2 ; j=1)$ and how it affects the two sides of the platform, i.e. the advertising volume and the number of readers. Using the setting of a digital platform above, and assuming that $p_{x_{1}}^{2}>0$ and $p_{x^{2}}^{1} \leq 0$, equation (18) yields a negative response in advertising volume to the taxation of

\footnotetext{
${ }^{22}$ See The Bookseller (2016), for instance.

${ }^{23}$ For a full assessment of the effects of a lower tax on electronic newspapers, we should also account for possible substitution effects between printed and electronic newspapers. To the extent that the two newspaper formats are perceived to be substitutes from the readers' perspective, readers might switch to printed newspapers in response to a higher price for electronic newspapers. This puts a cap on the price increase, but will not eliminate the basic incentive to set a higher subscription price on the newspaper which is now taxed at a lower rate. See Foros et al. (2016) for a discussion.

${ }^{24}$ See OECD (2013), for instance.
} 
ad revenues provided $\pi_{x^{1} x^{2}}>0$. In particular, when readers are indifferent towards ads, $p_{x^{2}}^{1}=0$, and the marginal cost of placing ads in electronic newspapers is zero, $C_{x_{2}}=0$, the sign of the response in ads is just equal to the sign of $\pi_{x^{1} x^{2}}$. So, the sign of $\pi_{x^{1} x^{2}}$ turns out to be of particular relevance for the tax analysis. Relatedly, from equation (19), the sign of the response in the number of readers to the advertising tax is negative when readers dislike ads and $\pi_{x^{1} x^{2}}>0$. The response in readership only becomes independent of the sign of $\pi_{x^{1} x^{2}}$ when readers are ad neutral.

By using equations (15) and (17) we find

$$
\pi_{x^{1} x^{2}}=p_{x^{2}}^{1}\left(1+\tau^{1}\right)^{-1}\left[1+\varepsilon_{x^{1}}\right]+p_{x^{1}}^{2}\left(1+\tau^{2}\right)^{-1}\left[1+\varepsilon_{x^{2}}\right]-C_{x^{1} x^{2}},
$$

where $\varepsilon_{x^{1}} \equiv \frac{x^{1}}{p_{x^{2}}^{1}} \frac{\partial p_{x^{2}}^{1}}{\partial x^{1}}$ and $\varepsilon_{x^{2}} \equiv \frac{x^{2}}{p_{x^{1}}^{2}} \frac{\partial p_{x^{1}}^{2}}{\partial x^{2}}$. The cross derivative $\pi_{x^{1} x^{2}}$ measures how the marginal profitability of selling newspapers, $\pi_{x^{1}}$, changes if the advertising volume increases. One might think that $\pi_{x^{1} x^{2}}$ is negative, given the assumption that the willingness to pay for the newspaper is likely decreasing in the advertising volume $\left(p_{x^{2}}^{1}<0\right)$. However, if the elasticity of $p_{x^{2}}^{1}$ with respect to $x^{1}$ is smaller than minus one $\left(\varepsilon_{x^{1}}<-1\right)$, the first term in equation $(23)$ is positive. The interpretation of the second term in (23) is similar; this term is positive for $p_{x^{1}}^{2}>0$ if $\varepsilon_{x^{2}}>-1$. Clearly, we might therefore have $\pi_{x^{1} x^{2}}>0$, and we are not aware of any empirical studies which can help us determine the sign. We shall therefore consider both the case of $\pi_{x^{1} x^{2}} \geq 0$ and $\pi_{x^{1} x^{2}}<0$ to be of relevance. ${ }^{25}$

The finding that advertising levels might rise with taxes contrasts with the conventional wisdom that a tax lowers economic activity that is subject to the tax, an insight that guides policy discussions on taxing advertising. For instance, the fact that people dislike ads in media products, at least on the margin, has prompted worries about possible excessive advertising from the society's point of view, and has lead European countries to restrict the amount of TV commercials or to consider taxes as a corrective device. ${ }^{26} \mathrm{~A}$ policy conclusion based on the analysis above is that a unit tax on ads is a more promising tax instrument. The response to a unit

\footnotetext{
${ }^{25} \mathrm{Kind}$ et al. (2009a) provides examples of when $\pi_{x^{1} x^{2}}$ is positive or negative.

${ }^{26}$ It is well documented that viewers try to avoid advertising breaks on TV, see Moriarty and
} 
tax on ads in a two-sided market is independent of the sign and magnitude of intergroup spillovers and unambiguously leads to a decline in ad quantities. ${ }^{27}$ This policy conclusion has merits not only based on the potential of having positive quantity responses with ad-valorem taxes, but also based on the possibility that platforms might charge no price on the non-advertising side of the platform. For instance, accessing the basic search services by Google or the basic communication services by Skype is free of charge and the implicit price users have to pay is the nuisance cost due to the exposure to advertising (provided they are ad averse). Most of the revenues of Google and Skype are generated by selling advertising space. Whenever the marginal cost of placing ads is zero, the ad-valorem tax on ads is neutral for price and quantity choices. ${ }^{28}$ This does not apply with unit taxes on ads.

There is a recurrent discussion in the US on whether to levy sales taxes on advertising or to limit the deductibility of advertising expenses for the purpose of corporate taxation. $^{29}$ In the current model, VAT and sales taxes are equivalent which implies that the results derived so far equally apply to a sales tax. The latter proposal can be straightforwardly linked to the model. A limited deductibility of advertising expenses on the part of advertising firms acts like a sales tax which is levied at the firm level. ${ }^{30}$ Thus, we can invoke the tax-side equivalence result Everett (1994), Danaher (1995), and Wilbur (2008). For printed newspapers there are some indications that the extent to which people consider commercials as bad varies across countries (Gabszewicz et al., 2004). Concerns about health implications of advertising consumption are raised in APA (2004).

${ }^{27}$ The negative response to taxes in a two-sided market can be established in a similar way as for the case of a newspaper tax that has been formally analyzed above.

${ }^{28}$ With automated selling and placing of ads on Google internet pages or on Skype interfaces a marginal cost of zero might well be a good approximation of cost structures.

${ }^{29}$ See Association of National Advertisers (2016) and The Advertising Coalition (2016), for instance.

${ }^{30}$ For instance, under the proposal launched in 2014, 50 percent of certain ad expenses would be deductible currently, and the other 50 percent would be amortized over either a five or ten year period (The Advertising Coalition, 2016). The delay in expensing incurs a cost in present value terms to the firm and acts like a tax on sales. 
to infer that such a tax will generate identical incidence and efficiency effects as the advertising tax $\tau^{2}$. For instance, when the platform only generates advertising income and the marginal costs of advertising are zero, the implicit tax due to the limited deductibility provision will be shifted onto the platform, leaving quantity choices and tax-inclusive prices for advertisers and the platform unchanged.

We might summarize the discussion so far as follows:

Proposition 3: Consider a two-sided media platform.

(i) A higher ad valorem tax on either side of the market might imply that output on both sides of the market increases $\left(d x^{i} / d \tau^{i}>0\right.$ and $\left.d x^{j} / d \tau^{i}>0, i, j=1,2\right)$. In particular, this might hold for digital media platforms where readers are ad averse while advertisers welcome readers.

(ii) A higher unit tax on either side of the market unambiguously yields negative own-tax responses $\left(d x^{i} / d t^{i}<0\right)$, whereas the cross-tax response might be positive $\left(d x^{j} / d t^{i}>0\right)$.

\subsubsection{Welfare effects of taxation}

With imperfect competition, taxes can be efficiency improving for two reasons. They may address inefficiencies due to market power and due to the insufficient internalization of intergroup spillovers in demand. As shown in Kind et al. (2008), the extent to which the platform internalizes the intergroup externalities can be measured by

$$
\Omega^{j} \equiv x^{j} p_{x^{i}}^{j}-\int_{0}^{x^{j}} p_{x^{i}}^{j} d \tilde{x}^{j}
$$

The term $\Omega^{j}$ measures the difference in the spillovers internalized by the platform,

$x^{j} p_{x^{i}}^{j}$, and by the social planner, $\int_{0}^{x^{j}} p_{x^{i}}^{j} d \tilde{x}^{j}$. If the platform correctly internalizes the spillovers from a social point of view, we thus have $\Omega^{j}=0$.

Note, the last term is related to the social spillover term $\phi_{x^{i}}^{j}\left(x^{i *}, x^{j *}\right)$ in $(16)$ through the relation

$$
\phi_{x^{i}}^{j}\left(x^{i}, x^{j}\right)=\int_{0}^{x^{j}} \phi_{x^{i} x^{j}}^{j}\left(x^{i}, \tilde{x}^{j}\right) d \tilde{x}^{j}=\int_{0}^{x^{j}} p_{x^{i}}^{j}\left(x^{i}, \tilde{x}^{j}\right) d \tilde{x}^{j} .
$$


In general, the platform internalizes the intergroup externalities, but perhaps not perfectly so from a social point of view. The platform accounts for how a larger output of good $i$ affects the willingness to pay for the marginal unit of good $j$, while a social planner also cares for the change in the valuation for inframarginal units. To illustrate the reasoning in the context of a media market, suppose that newspapers readers are ad averse $\left(p_{x^{2}}^{1}<0\right)$ and that readers with a high willingness to pay for newspapers are most ad averse, i.e. $p_{x^{2}}^{1}$ is increasing in $x^{1}$. Now, the platform accounts only for the effect of advertising on the marginal reader and ignores the larger effect on the average reader. Formally, we have $\int_{0}^{x^{1}} p_{x^{2}}^{1} d \tilde{x}^{1} / x^{1}<p_{x^{2}}^{1}$, implying that $\Omega^{1}>0 .{ }^{31}$

The government can achieve first-best outputs under imperfect competition by appropriately choosing ad valorem taxes. Defining welfare as the sum of consumer surplus across the two groups, firm profits and tax revenues, it can be shown that the optimal ad valorem taxes that reproduce the first-best output levels are

$$
\tau^{i *}=\frac{\left(p^{j *}+x^{j *} p_{x^{j}}^{j *}\right)\left(\Omega^{j *}+x^{i *} p_{x^{i}}^{i *}-x^{j *} p_{x^{i}}^{j *}\left(\Omega^{i *}+x^{j *} p_{x^{j}}^{j *}\right)\right.}{\left(p^{j *}+x^{j *} p_{x^{j}}^{j *} C_{x^{i}}^{*}-x^{j *} p_{x^{i}}^{j *} C_{x^{j}}^{*}\right.} .
$$

Comparing (26) with (13), the optimal tax rates differ from the optimal tax rates on printed books and ebooks by the existence of demand spillovers that are not internalized by the market. The term $\Omega^{j *}$ measures the difference in the spillovers internalized by the monopolist and the social planner, c.f. (24). ${ }^{32}$ As shown in Kind et al. (2008), this feature of a two-sided market might create a diversity of optimal tax policies depending on the degree to which intergroup spillovers are internalized by the platform and to which quantity responses to taxes are conventional. For instance, in the context of a digital platform in the media industry, we might have $p_{x^{1}}^{2}>0, p_{x^{2}}^{1} \leq 0$ and $C_{x^{1}}=0$. Provided $\pi_{x^{1} x^{2}}>0$ the quantity response $d x^{1}$ to

\footnotetext{
${ }^{31}$ Note that this outcome resembles the result that a monopolist may oversupply quality compared to what a social planner would do for any given output (e.g. Tirole, 1988, Spence, 1975).

${ }^{32}$ As mentioned above, two-sidedness differs from the theory of complementarity or substitutability by the existence of demand spillovers that might not be internalized by the market and so do the optimal tax rates in the two economic environments, c.f. (13) and (26).
} 
a higher $\operatorname{tax} \tau^{1}$ is positive. Whenever the newspaper is overprovided, i.e. $\Omega^{2 *}+$ $x^{1 *} p_{x^{1}}^{1 *}>0$, the optimal tax turns out to be negative. The overprovision tendency can be neutralized by subsidizing newspaper sales.

We have:

Proposition 4: Consider a two-sided media platform. If output is socially excessive, the optimal tax policy might call for a lower VAT rate on the service that is overprovided.

Efficient tax treatment of digital platforms could be hindered by the existence of fiscal competition. National governments might only be able to determine the tax rate that applies to one stream of revenues while the tax treatment of the second revenue stream is chosen by a different national government. A case in point is Google, which offers services in different countries in the European Union. The revenue coming from the service provision is taxable in the country in which the service is consumed. However, advertising income typically accrues to a subsidiary in a low-tax country (like Ireland). Presumably, the low tax rates are due to fiscal competition. ${ }^{33}$ Thus, we will now analyze the welfare effects of the downward pressure on the tax on advertising revenues by marginally increasing the tax rate. Thereby, we look at how raising the ad tax $\tau^{2}$ influences joint welfare of the two jurisdictions in which the platform resides. One might conjecture that the effect of a downward pressure on $\tau^{2}$ in fiscal competition is detrimental to welfare since it might generally raise ad quantities which create nuisance costs on the part of media users. To illustrate the possibility that this conjecture is erroneous, we resort to an example which shows that even though the consumers by assumption perceive ads

\footnotetext{
${ }^{33}$ Although the tax rate that applies to advertising revenues in Ireland is the Irish profit tax, the model can be used to analyze the profit tax implications. To the extent that not all costs of the Irish subsidiary can be deducted from the Irish profit tax base (as is typically the case with the cost of equity finance, for instance), the tax structure imposed on the model is suitable to look at the implications of profit taxation.
} 
as a bad, it might be harmful for both the consumers and the society as a whole if ads are taxed. To illustrate this insight we resort to the following example.

Example 2: We follow Godes et al. (2009) and Kind et al. (2007, 2009) in assuming that consumer demand for the newspaper is given by the inverse demand function

$$
p^{1}=1-x^{1}-\gamma x^{2}
$$

where $\gamma$ is a positive parameter which measures the readers' dislike for ads; the higher $\gamma$, the greater the consumers' disutility of ads. ${ }^{34}$ In the following we focus on the sensitivity of prices and quantities to the degree of ad aversion, a parameter which presumably is most central to policy discussions on the desirability of an ad tax.

Let the inverse demand curve for ads be given by

$$
p^{2}=1-\left(p^{1}+2 \gamma x^{2}\right) .
$$

The willingness to pay for an ad in newspaper $i$ is thus decreasing in its advertising volume $\left(p_{x^{2}}^{2}<0\right)$ and in the consumer price of the newspaper $\left(p_{p^{1}}^{2}<0\right)$. The reason for the latter is that a higher newspaper price tends to reduce newspaper circulation, thereby making advertising less attractive.

Maximizing newspaper's profit (15), while setting $\tau^{1}=0$, yields quantity choices

$$
x^{1}=\frac{8 \gamma}{D} \text { and } x^{2}=\frac{4\left(1-\gamma\left(1+\tau^{2}\right)\right)}{D} .
$$

The denominator $D$ is positive when the second-order conditions and the nonnegativity constraints are satisfied. ${ }^{35}$ Inserting the quantity choices into the inverse demand functions (27) and (28), it follows that non-negative prices require $\gamma \in(1 / 3,1)$.

\footnotetext{
${ }^{34}$ Thus, the term $p^{1}+\gamma x^{2}$ might be referred to as the hedonic price for newspapers.

${ }^{35} \mathrm{~A}$ proof is available upon request.
} 
Defining welfare $W$ as the sum of consumer surplus, profit and tax revenues in the two jurisdictions, it can be shown that, for a small tax increase from $\tau^{2}=0$,

$$
\left.\frac{d W}{d \tau^{2}}\right|_{\tau^{2}=0}=-2 \frac{\gamma(1-\gamma)\left(1+7(\gamma)^{2}\right)}{(D)^{3}}<0
$$

Even though advertising imposes a negative externality on newspaper readers, a tax on ads consequently has a negative effect on welfare. The negative welfare effect is not only due to a drop in profits. Consumer surplus equally declines. ${ }^{36}$

Let us now look at the reason for this somewhat paradoxical result. First, note that the media firm's pricing decision correctly includes the nuisance cost of advertising. This follows because

$$
x^{1} p_{x^{2}}^{1}=\gamma x^{1} \quad \text { and } \quad \int_{0}^{x^{1}} p_{x^{2}}^{1} d \tilde{x}^{1}=\gamma x^{1}
$$

with the consequence of $\Omega^{1}=0$, c.f. (24). The marginal effect and the social average effect (per reader) coincide for an inverse demand function for newspapers which is linear in the amount of advertising. An analogue reasoning applies to the spillovers that newspapers generate. Thus, there is no market failure here with respect to the platform's response to consumer disutility of ads. Consequently, welfare falls due to the fact that the media firm reduces both quantities in response to the ad tax. ${ }^{37}$ This is bad from a social point of view.

The concern that some electronic platforms shift income, which is mainly advertising income, to low-tax jurisdictions has raised demands in various countries to switch to a source-based tax on sales revenues ('Google taxation'). ${ }^{38}$ However, as shown in the example above, this could have unintended negative side effects

\footnotetext{
${ }^{36}$ Consumer surplus is $C S=\left(x^{1}\right)^{2}$ which negatively depends on taxes through the negative quantity response $d x^{1} /\left.d \tau^{2}\right|_{\tau^{2}=0}=-2 \gamma\left(1-(\gamma)^{2}\right) /(D)^{2}<0$.

${ }^{37}$ This follows because $\Pi_{a n}=\left(1+\tau^{2}\right)^{-1}-\gamma>0$, c.f. (18).

${ }^{38}$ See GALA (2014) for a discussion of the introduction of a 'Google' tax in Hungary and Forbes (2013) for a general discussion of such a tax in France. Relatedly, as of April 2016, the UK government has introduced a change in the flow of advertising revenues of Facebook in the UK, where for larger advertisers the advertising income must be reported by Facebook UK rather than by Facebook Ireland. However, the change in flow of income might be neutralized by corresponding
} 
in terms of efficiency, just because it may bring advertising volume below social optimum.

\section{Conclusion}

Digital goods and digital platforms have vastly grown in importance over the last decade. A tax policy that aims at levelling the playing field between digital products and their non-digital counterpart might have unintended effects. For instance, applying the same favorable VAT rate that is levied on printed books to ebooks may have negative welfare effects. Similarly, network effects between the reader and advertising side may render a low-tax treatment of digital newspapers detrimental for circulation. A preferential tax treatment may thus be an inappropriate policy to increase the size of readership. Even though our discussion primarily focuses on ebooks and digital newspapers, the effects we highlight are present also for other kinds of goods. For instance, downloadable music and conventional CD's are not explicitly analyzed in the paper, but can be readily subsumed in the models that we elaborate in the paper.

Let us finally note that a large strand of the media economics literature assumes Hotelling competition (with Anderson and Coate, 2005, as the seminal paper). The implications of VAT in such frameworks have been analyzed in Kind et al. (2010) and Kind et al. (2013). However, this literature assumes that consumers singlehome, i.e. that each consumer buys at most one newspaper. Then there will be no competition between the platforms in the advertising market, since the advertisers can reach any given consumer only through one particular media platform. However, recent contributions by Ambrus et al. (2016), Athey et al. (2016) and Anderson et al. (2016a,b) allow consumers to multi-home (buy more than one newspaper). An adjustments in the flow of royalty payments from Facebook UK to the headquarter of Facebook on the Cayman Islands (The Guardian, 2016). The taxable income in the UK might be speculated not to change too much and the tax implications analyzed above might continue to be of relevance. 
interesting path for future research would be to investigate how this will affect the consequences of taxing digital goods.

\section{References}

[1] Agrawal, D. and W. Fox (2016), Sales Taxes in an E-Commerce Generation, mimeo, University of Kentucky.

[2] Ambrus, A., E. Calvano, and M. Reisinger (2016), Either or both competition: A "two-sided" theory of advertising with overlapping viewerships, American Economic Journal: Microeconomics. Forthcoming.

[3] Anderson, S., Ø. Foros, and H. J. Kind (2016a), Competition for advertisers and for viewers in media markets, Economic Journal. Forthcoming.

[4] Anderson, S., Ø. Foros, and H. J. Kind (2016b), 'Product functionality, competition, and multi-purchasing, International Economic Review. Forthcoming.

[5] APA (2004), American Psychological Association. Report of the APA Task Force on Advertising and Children. February 23, 2004. Available at:http://www.apa.org/pi/families/resources/advertising-children.pdf. Accessed 15 April 2016.

[6] Anderson, P.S. and S. Coate (2005), Market Provision of Broadcasting: A Welfare Analysis, Review of Economic Studies, 72, 947-972.

[7] Anderson, S. and J. Gabszewicz (2006), The Media and Advertising: A Tale of Two-Sided Markets, in: V.A. Ginsburgh (ed.), Handbook of the Economics of Art and Culture, 567-614 (North-Holland, Amsterdam).

[8] Armstrong, M. (2006), Competition in Two-Sided Markets, Rand Journal of Economics, 37, 668-691. 
[9] Auerbach, A. and Hines, J. (2002), Taxation and Economic Efficiency, in: A. Auerbach and M. Feldstein (eds.), Handbook of Public Economics, vol. 3, Chapter 21. North-Holland.

[10] Association of National Advertisers (2016), Tax Plans That Include Amortization Proposals Being Considered By Congress (https://www.ana.net/content/show/id/adtax. Accessed: 15 April 2016).

[11] Athey, S., E. Calvano, and J. Gans (2016), The Impact of Consumer MultiHoming on Advertising Markets and Media Competition, Working paper.

[12] The Bookseller (2016), EC commits to lowering ebook VAT (http://www.thebookseller.com/news/ec-committs-addressing-ebook-vatinequality-action-plan-326076. Accessed: 8 April 2016).

[13] Caillaud, B. and B. Jullien (2003), Chicken and Egg: Competition Among Intermediation Service Providers, Rand Journal of Economics, 34, 309-328.

[14] Danaher, P. (1995), What Happens to Television Ratings During Television Commercials?, Journal of Advertising Research, 35, 37-48.

[15] Depken II, C. A. and D. P. Wilson (2004), Is Advertising Good or Bad? Evidence from U.S. Magazine Subscriptions, Journal of Business, 77, S61-S80.

[16] Delipalla, S. and M. Keen (1992), The Comparison between Ad valorem Taxes and Specific Taxation under Imperfect Competition, Journal of Public Economics, 49, 351-367.

[17] EFTA Surveillance Authority (2016), Case No. 78337, Document No. 776581, Decision No 023. Raising no objections to a zero VAT rate for electronic news services (Norway). Available at http://www.eftasurv.int/media/esadocs/physical/776581.pdf. 
[18] European Commission (2014), Report of the Commission Expert Group on Taxation of the Digital Economy, Brussels.

[19] European Commission (2016), VAT Rates Applied in the Member States of the European Union, Taxud.c.1(2016), Brussels.

[20] Evans, D. S. (2003), Some Empirical Aspects of Multi-Sided Platform Industries, Review of Network Economics, 2 , 191 - 209.

[21] Forbes (2013), The French Try another Tax on Facebook, Google and YouTube (http://www.forbes.com/sites/timworstall/2013/12/27/the-frenchtry-another-tax-on-facebook-google-and-youtube/257de4070289. Accessed: 14.04.2016).

[22] Foros, Ø., H.J. Kind and G. Shaffer (2014), Turning the Page on Business Formats for Digital Platforms: Does the Agency Model Soften Competition?, Working Paper, Norwegian School of Economics, Bergen.

[23] Foros, Ø., H.J. Kind and T. Wyndham (2016), Taxation of Newspapers when Consumers Multihome, unpublished manuscript.

[24] Gabszewicz, J. J., D. Laussel, and N. Sonnac (2004), Attitudes Towards Advertising and Price Competition in the Press Industry, in: V.A. Ginsburgh (ed.), Economics of Art and Culture, Elsevier, 61-74 (North-Holland, Amsterdam).

[25] GALA (2016), Hungarian Advertisement Tax - The New Google Tax? (http://www.mondaq.com/x/361762/tax+authorities /Hungarian+Advertisement+Tax+The+New+Google+Tax. Accessed: 14.04.2016).

[26] Godes, D., E. Ofek, and M. Sarvary (2009), Content vs. Advertising: The Impact of Competition on Media Firm Strategy, Marketing Science, 28, 20-35. 
[27] Goldfarb, A., S.M. Greenstein, and C.E. Tucker (eds.) (2015), Economic Analysis of the Digital Economy, NBER conference report, The University of Chicago Press.

[28] Kind, H.J., M. Koethenbuerger, and G. Schjelderup (2008), EfficiencyEnhancing Taxation in Two-Sided Markets, Journal of Public Economics, 92, 1531-1539.

[29] Kind, H.J., M. Koethenbuerger, and G. Schjelderup (2009a), Should UtilityReducing Media Advertising be Taxed?, CESifo Working Paper Series 2589, CESifo Group Munich.

[30] Kind, H.J., M. Koethenbuerger, and G. Schjelderup (2009b), Welfare- and Revenue-Dominance of Ad Valorem Taxation in Two-Sided Markets, Economics Letters, 104,86-88.

[31] Kind, H.J., M. Koethenbuerger, and G. Schjelderup (2010), Tax Responses by Platform Industries, Oxford Economic Papers, 62, 764-783.

[32] Kind, H.J., T. Nilssen, and L. Sørgard (2007), Competition for Viewers and Advertisers in a TV Oligopoly, Journal of Media Economics, 20(3), 211-233.

[33] Kind, H.J., T. Nilssen, and L. Sørgard (2009), Business Models for Media Firms: Does Competition Matter for how They Raise Revenue?, Marketing Science, 28, $1112-1128$.

[34] Kind, H.J., G. Schjelderup and F. Stähler (2013), Newspaper Differentiation and Investments in Journalism: The Role of Tax Policy. Economica, 80, 131148.

[35] Lockwood, B. (2001), Tax Competition and Tax Co-ordination under Destination and Origin Principles: a Synthesis, Journal of Public Economics, 81, 279-319. 
[36] Moriarty, S. E. and S.L. Everett (1994), Commercial Breaks: A Viewing Behaviour Study, Journalism Quarterly, 71, 346-355.

[37] Ng, Y.K. (1980), Optimal Corrective Taxes or Subsidies when Revenue Raising Imposes an Excess Burden, American Economic Review, 70, 744-751.

[38] OECD (2013), Action Plan on Base Erosion and Profit Shifting, Paris.

[39] Rochet, J.C. and Tirole, J. (2003), Platform Competition in Two-Sided Markets, Journal of the European Economic Association, 1, 990-1029.

[40] Rochet, J.C. and J. Tirole (2006), Two-Sided Markets: An Overview, Rand Journal of Economics, 37, 645-667.

[41] Sadka, E. (1978), On the Optimal Taxation of Consumption Externalities, Quarterly Journal of Economics, 92, 165-174.

[42] Sandmo, A. (1975), Optimal Taxation in the Presence of Externalities, Swedish Journal of Economics, 77, 86-98.

[43] Spence, M. (1975), Monopoly, Quality and Regulation, The Bell Journal of Economics 6, 417-429.

[44] Shubik, M. and R. Levitan (1980), Market Structure and Behavior. Harvard University Press.

[45] Suits D. and R. Musgrave (1953), Ad Valorem and Unit Taxes Compared, Quarterly Journal of Economics 67, 598-604.

[46] The Advertising Coalition (2016), Federal Efforts to Limit Advertising (http://theadvertisingcoalition.com/on-the-issues. Accessed 15 April 2016).

[47] The Guardian (2016), Facebook to Pay Millions more in UK Tax (https://www.theguardian.com/technology/2016/mar/04/facebook-paymillions-more-uk-tax-reports. Accessed 18 July 2016). 
[48] Tirole, J. (1988), Industrial Organization, Massachusetts, MIT Press.

[49] Wilbur, K. C. (2008), A Two-Sided, Empirical Model of Television Advertising and Viewing Markets, Marketing Science 27, 356-378.

[50] Wischenbart, R. and J. Celaya (2014), The Global ebook Report: A Report on Market Trends and Developments, 3rd Edition, Rüdiger Wischenbart Content and Consulting. 